\title{
Preferences for support services among adolescents and young adults with cancer or a blood disorder: a discrete choice experiment.
}

\author{
Authors \\ Stephen Goodall1, Madeleine King2, Jane Ewing3, Narelle Smith3, Patricia Kenny1 \\ 1 Centre for Health Economics Research and Evaluation, University of Technology, \\ Sydney \\ 2 Quality of Life Office, Psycho-Oncology Cooperative Research Group, University of \\ Sydney, Sydney, Australia \\ 3 Department of Mathematical Sciences, University of Technology, Sydney
}

\section{Corresponding Author}

Dr Stephen Goodall, Senior Lecturer in Health Economics

Centre for Health Economics Research \& Evaluation (CHERE), University of

Technology, Sydney, PO Box 123 Broadway NSW 2007

E-Mail: stephen.goodall@chere.uts.edu.au

Tel + 6129514 4752, Fax + 61295144730 


\section{Abstract}

Background: Life-threatening illnesses in young people are traumatic for patients and their families. Support services can help patients and families deal with various non-medical impacts of diagnosis, disease and treatment. The aim of this study was to determine which types of support are most valued by adolescents and young adults (AYA) with cancer or blood disorders and their families.

Method: A discrete choice experiment (DCE). Separate experiments were conducted with AYA and their carers.

Results: Completed surveys were returned by 83 patients and 78 carers. AYA preferred emotional support for themselves (either by counsellors and/or peers), emotional support for their family, financial support and assistance returning to school/work over services relating to cultural and spiritual needs. Covariate analysis indicated female AYA were more likely than males to prefer emotional support, while males were more likely to prefer assistance returning to work/school. Carers preferred emotional support for their AYA and assistance returning to school/work. Like AYA, they were indifferent about services relating to cultural and spiritual needs.

Conclusion: Providing the types of support services that people prefer should maximise effectiveness. This study suggests that AYA patients require support services that included financial aid, assistance returning to work/study, emotional support for themselves and for their family. 


\section{Introduction}

The diagnosis and treatment of life-threatening illnesses can be a traumatic experience for patients and their families. The diseases themselves can cause symptoms, such as fatigue and pain, whilst common treatments such as chemotherapy, radiotherapy, and surgery can have deleterious side-effects as well as beneficial effects $[1,2]$. Support services can help patients and families deal with various non-medical impacts of diagnosis, disease and treatment. There is considerable evidence demonstrating the benefits of psychosocial interventions in reducing morbidity and improving quality of life of cancer patients [3-5]. However, there is limited published evidence pertaining to the types of services, particularly social and emotional support required during periods of diagnosis, treatment and follow-up $[6,7]$.

Adolescents and young adults (AYA) with cancer or blood disorders present unique age-specific support challenges. These patients face a number of aspects that may compromise their well-being and psychosocial functioning. These include; mortality issues, difficulties adjusting to living with uncertainty, the knowledge that the condition may be life-long and the possibility of recurrence $[8,9]$. Patients may experience the loss of peers with similar conditions and the fear, restrictions and overprotectiveness of their parents may also influence the perceptions young patients have of their ability to adapt to appropriate development stages [10,11].

Early studies in psychosocial functioning of chronically ill adolescents found significant emotional problems and poor social adaptation $[12,13]$. However, more recent evidence suggests that children with chronic illnesses do not manifest psychological disturbance or maladjustment and may utilise internal resources, resiliency, practical resources and social support as effective coping mechanisms [12, 14]. The relationship between social support and health behaviours is well 
characterised. Evidence suggests that social support has both a direct positive effect on health status and also serves as a modifier of stress on the mental and physical health of an individual [15].

A strong social support system is a significant resource for children with cancer and their families coping with the illness [16-18]. Social support and family serve as a variable in future orientation among AYA [19]. Adolescents with more social support report less psychological distress or higher coping scores [18, 20]. A strong social support system is especially important in helping them cope with both the complex normative development tasks, faced by all adolescents, as well as cancer-related stressors [21]. The evidence pertaining to the support needs of AYA with a blood disorder is limited. Bush et al [22], demonstrated that perceived social and emotional support was greater in a thalassaemia group than in healthy controls (controls were matched by age, demographic and socio-economic status).

Support requirements are not confined to the patient as cancer diagnosis also impacts the family and wider social network. Parents highlighted they required more counselling opportunities, including informal and formal services for emotional support and service guidance [23]. Practical considerations are important since families may experience upheavals in daily lives. Parents (or caregivers) have to manage their time between caring responsibilities and everyday domestic tasks [24, 25]. Disturbances to employment patterns may have important financial implications, in addition to any extra expenditure incurred [26, 27].

A recent study by Rankin et al [7] presented an overview of selected psychosocial oncology services in NSW and identified the challenges faced by these services. Less than half of staff surveyed said there was adequate provision of psychosocial support, 
with the majority of sites reporting that they could only provide limited support services. About two-thirds of sites were able to offer support in the form of travel assistance for rural patients, financial advice and pastoral care. Support groups and support programs were not commonly available, with survivorship programs being offered in less than a quarter of sites. The study confirms that psychosocial oncology services are not well defined structurally.

The study by Rankin et al provides a fascinating insight into how oncology support services are provided in Australia[7]. However, the study is limited because it focuses entirely on the views of the health care provider rather than the views of the patient or carer. We aim to address this shortcoming by adopting a patient and carer perspective. The aim of this study was to use a discrete choice experiment (DCE) to determine which types of support are most valued by AYA with cancer or blood disorders and their families. DCEs provide an alternative methodology to estimate preferences for support services. DCEs are based on Lancaster's economic theory of value where individuals derive utility from the underlying attributes of a good, and preferences (and thus utility) across goods are revealed through their consumption choices[28]. DCEs involve respondents choosing their preferred alternative from a series of hypothetical choice sets, where each alternative is described by a bundle of attributes and each attribute is described by levels which differ across choice sets. The strength of the DCE approach is that choosing between bundles of goods is an easily comprehended task for respondents and there is evidence that it is both consistent with welfare theory[29] and consistent with that observed in practice[30].

This study adds to the literature in a number of ways. First, previous studies have either used standard survey techniques or qualitative methodologies to identify preferences for support services; we use a DCE. Second, most studies have tended to focus on one dimension of support, whilst the conceptual definition of social support 
is multi-dimensional - by using a DCE design we avoid this issue. Third, interactions with covariates (such as diagnosis and gender) can be taken into account and tested. Finally, by including patients with cancer and blood disorders and their carers, we are able to test if a 'one-size fits all' program of support services is appropriate.

\section{Methods}

\section{Participants}

AYA inclusion criteria were: aged 16-32 years old and diagnosed with cancer or a blood disorder at least three month prior to recruitment (to allow participants time to adjust to their diagnosis and treatment). AYA exclusion criteria were: inability to read and write English; co-morbidity; major developmental disorder; receiving end-of-life care; recently diagnosed; or involved in a concurrent "late effects" study. Nominated carers were also recruited; the only exclusion criterion was lack of English literacy. Recruitment occurred from $1^{\text {st }}$ July 2003 to $31^{\text {st }}$ May 2004 via three Sydney hospitals: Sydney Children's Hospital, Prince of Wales Hospital, and Royal Hospital for Women. Eligible AYA participants were identified from databases or patient records by a member of the medical team and permission was sought to approach eligible patients. Participants were recruited into the study following an introductory letter from their treating clinician. Permission was gained from AYA participants to approach their nominated carer. All participants provided informed written consent.

\section{Data collection}

AYA participants were given at clinic, on wards or posted a booklet containing a set of questionnaires including the DCE, questions about their current disease, treatment, 
and socio-demographics. Each carer received a booklet containing parallel versions of the AYA booklet [31].

\section{DCE design}

The AYA and carer DCEs were both unlabelled. Each hypothetical choice set comprised two packages of support services. After reading each choice set, participants (and carers) were asked to choose either service plan A or service plan B. The attributes used in each experiment (Table 1) were developed for the study, based on the published literature describing the role and support needs of AYA patients with life threatening conditions. These attributes and levels were refined based on feedback from two focus groups; one comprised 12 AYA patients and family members and the other comprised eight health and allied health professionals who cared for AYA patients.

Descriptions of each attribute were provided to the participant.

Both DCEs used six attributes (4 with 2 levels and 2 with 4 levels) to describe the type of support service, see Table 1. The full factorial design (all possible combinations of attributes and levels) was used, giving 256 possible choice sets. Choice sets were randomly assigned to one of 16 versions. Each participant (and carer) was asked to answer 16 choice decisions.

Insert Table 1: Attributes and levels.

\section{Statistical analysis}

It was assumed that each respondent's utility function can be described using a random utility model [32], which are derived under the assumption of utilitymaximizing behaviour by the decision maker. Where $\mathrm{U}_{\mathrm{ij}}$ represents individual $i$ 's utility from support service $j, \mathrm{~V}_{\mathrm{ij}}$ represents the systematic component of individual $i$ 's 
utility function of support service $j$ and $\varepsilon_{\mathrm{ij}}$ represents individual $i$ 's random utility component of support service $j$.

$$
U_{i j}=V_{i j}+\varepsilon_{i j}
$$

It was assumed that the systematic component $\mathrm{V}_{\mathrm{ij}}$ is a linear combination of an individual's inherent characteristics $Z_{\mathrm{i}}$ (such as gender or other demographic factors) and the attributes of the support service $X_{\mathrm{ij}}$ (such as whether the service offers financial or emotional support), where $\beta$ and $\gamma$ are vectors of coefficients

$$
V_{i j}=\beta X_{i j}+\gamma Z_{i}
$$

Consequently the probability of preferring support service A versus support service B is due to both a systemic component and some random component. It is assumed that in a given scenario, the respondent would choose the alternative that provides the greatest utility; hence choosing alternative $j$ if and only if $U_{i j}>U_{i h} \forall h \neq j$.

\section{Data Analysis}

Data were analysed in STATA using: 1) a conditional logit model [32], which assumes common tastes for the observed attributes and the errors are independent and identically distributed; and 2) a mixed (random effects) logit model [33] (200 Halton draws), which allows for taste heterogeneity but assumes that tastes in different attributes are independent. Sub-group analysis was conducted by interacting demographic variables with support service attribute. This assumes there is a homogeneous shift in the mean impact of the support service attribute but the distribution remains the same. 


\section{Calculating Predicted Probabilities}

The probability that individual $i$ chooses $j$ in scenario $s$ is:

(3) $\quad P_{i s j}=\frac{\exp \left(X_{i s j}^{\prime} \beta\right)}{\sum_{h} \exp \left(X_{i s h}^{\prime} \beta\right)}$.

The probability of choosing each option, as predicted by the model, was estimated using simulation. The simulation took 1000 random draws from the estimated normal distribution of each random parameter and the probability in equation 3 was estimated for each draw. The reported probability is the mean of the 1000 replications. The Probability of choosing each attribute level was estimated as the probability of choosing a plan when it has that attribute level and the alternative is 0 (no support service), holding other attributes constant at 0 (no service). Given the choice was between two options, a probability of 0.50 would indicate indifference to the attribute level.

\section{Ethics}

The study was approved by the Scientific Review Committees of the South Eastern Sydney Area Health Service and Royal Hospital for Women, and the University of Technology Sydney Human Ethics Research Committee.

\section{Results}

Completed surveys were returned by 83 of the 88 AYA patients ( $94 \%$ response rate) and 78 of the 79 carers (99\% response rate). Of the 83 returned AYA surveys, four patients had only attempted one question and one patient only completed two questions, subsequently these surveys were omitted from the analysis. The remaining 
78 surveys were completed in full by 77 patients and one patient completed 15 scenarios, giving a total of 1247 observations. Of the 78 returned carer surveys, three carers had attempted one question only and one carer completed two questions only, subsequently these surveys were omitted from the analysis. The remaining 74 surveys were completed in full, giving a total of 1184 observations.

Table 2 shows the clinical and socio-demographic characteristics of the AYA and their carers. The age range of the AYA patients was 15 - 32 years and they were characterised as having either cancer (58) or a blood disorder (20). Cancer diagnoses included; leukaemia, Hodgkin's lymphoma, non-Hodgkin's lymphoma, Ewing's sarcoma, Wilm's tumour, neuroblastoma, carcinoma, osteosarcoma. Blood disorders included: thalassaemia, anaemia, sickle cell anaemia, von Willebrand's disease and haemophilia. Of the 79 carers, $86 \%$ were parents and $7 \%$ were partners of AYA.

\section{Insert Table 2 here}

\section{AYA estimates}

The non-labelled nature of the experiment was illustrated in the randomness of preferences for support service A and B. AYA chose support service A on 643 occasions (51.6\%) and support service B on 604 occasions (48.4\%). Likewise the carers chose A 50.9\% (603) and B 49.1\% (581).

The mixed logit analyses for AYA participants are presented in Table 3. The results are presented for the entire sample and for interactions with gender and type of illness. Respondents were more likely to prefer a support service that included financial aid, assistance returning to work/study, emotional support (either with a counsellor, peer or both) and emotional support for their family (either with a 
counsellor, peer or both). There was indifference to cultural targeted or spiritual support. With the exception of emotional support from peers, all estimated attribute level standard deviations were significant which suggests a high level of heterogeneity among participants' preferences for support services. Emotional support from peers was the one attribute level which was generally preferred

The interactions for gender demonstrate that, relative to females, males prefer more assistance returning to work, less emotional support for themselves, but more emotional support for their families. Interestingly male preferences for cultural specific support are negative and significant at a 5\% level, indicating a general tendency to value cultural support lower than females, however the significant standard deviation which is larger than the mean suggests that some males did value this. The interactions for type of illness demonstrate that AYA participants with blood disorders value more support returning to work and more emotional support for themselves.

\section{Insert Table 3 here}

\section{Carer estimates}

The mixed logit analysis for carers is presented in Table 4. As with the AYA cohort, carers were more likely to prefer a support service that included financial aid, assistance returning to work/study, emotional support for the patient (either with a counsellor, peer or both) and emotional support for themselves (either with a counsellor, peer or both). On average, there was indifference to cultural targeted or spiritual support, however the large and statistically significant standard deviation suggests that some valued this. All estimated attribute standard deviations were significant which suggests a high level of heterogeneity. 


\section{Predicted Probabilities}

The probabilities in Figure 1 illustrate the similarity in preferences between patients and carers. The probability of choosing the support service was highest when emotional support was provided for the patient, particularly if peer support was included (0.81). Culturally targeted support and spiritual support had little or no impact on the probability of choosing a support plan; the probability was close to 0.5 for both these services. Patients and carers appeared to differ somewhat in their preferences for emotional support for the family, where the probability of choosing plans with family emotional support was higher for patients by $10 \%$.

\section{Insert Figure 1 here}

\section{Discussion}

We assessed the stated preferences for support services in AYA patients with cancer or a blood disorder using a DCE. A parallel experiment was undertaken in their nominated carers. We demonstrate that, on average, AYA were more likely to prefer a support service that included financial aid, assistance returning to work/study, emotional support for themselves and for their family. There was indifference to cultural targeted or spiritual support. We also demonstrate that there was reassuring symmetry between the preferences of AYA and their nominated carer.

Previous studies have either used standard survey techniques or qualitative methodologies to identify need and preferences for support services for young people with chronic illness. Furthermore, most studies have tended to focus on one dimension of support, whilst the conceptual definition of social support is multi- 
dimensional. The main advantage of using DCE techniques to measure preferences for support services is that we are able to measure multiple service attributes in a single experiment and identify trade-offs, or preferences between attributes.

The demonstrated preference heterogeneity suggests that a 'one-size fits all' program of support services is unlikely to capture the differences in individuals' support needs. An advantage of this study design is that interactions with covariates can be taken into account, which may explain this heterogeneity. For example, the interactions for gender demonstrate that, relative to females, males preferred more assistance returning to work/study, and less emotional support for themselves but more emotional support for their families. Interestingly male preferences for cultural specific support are negative and significant, indicating a general tendency to value cultural support lower than females. The interactions for type of illness demonstrate that AYA participants with blood disorders value more support returning to work and more emotional support for themselves.

AYA with cancer have a network of both healthy and ill peers who play a significant role in their lives [34]. Friends who are healthy appear to help the individual relate to a period prior to their illness, and peers with cancer are able to empathise and understand the patient's current situation. Having 'someone to talk to' has been shown to be beneficial [8]. Therefore helping adolescents and young adult people with cancer to maintain family relationships, retain old friendships and develop new friendships are important elements of supportive care. Our findings support the importance of maintaining peer support.

Another consideration is preparation and support when returning to school or work. Research on children with cancer demonstrated that returning to school requires 
planning and coordination between the hospital, family and school [35]. Mitchell et al [23] highlighted that parents wanted more coordination transition services, such as an educational coordinator to oversee their child's re-entry into school. We believe that this study is the first to demonstrate the importance of providing AYA with assistance when returning to work/study after a period of illness.

Our data suggests considerable heterogeneity among individuals (AYA and their carers) regarding culturally specific or spiritual support. Elsewhere the evidence for the demand for spiritual based health care remains inconclusive. Most studies are undertaken in the United States, where attitudes to religious and spiritual belief may differ to those held in Australia, therefore direct comparison may be inappropriate. However, Taylor (2003)[36] demonstrated in adult cancer patients that some patients or caregivers do not want overt forms of spiritual care and others are eager for them. Our findings suggest that there was a lack of value assigned to spiritual or ethnic/cultural support services, therefore rather than offering these services providers should focus on offering emotional support and work/study support.

There are a number of limitations to the study. For some participants, much time may have passed since they were diagnosed with their illness. Unfortunately we did not record date of diagnosis; however this may not be such an issue because although two-thirds of our sample were off-treatment, almost half of those people were still experiencing moderate to severe symptoms. This suggests that, from a patient perspective, sympomatology may be more relevant to their support requirements than whether the patient is on or off-treatment.

Related to the above point, time from diagnosis may be a good indicator of adaptation and therefore inversely related to demand for support services. Intuitively patients 
recently diagnosed or on-treatment are more likely to have higher support

requirements. However, the counter argument could be that patients off-treatment are less likely to have access to health service support. From our data set, it was not possible to make this distinction between times of diagnosis. Clearly this relationship requires further investigation.

Finally, Rankin et al [7] concluded that the challenge most commonly reported by providers was having to provide patient care across a large geographical area. A review of rural and regional cancer services reported over half of participating cancer services identified an urgent need for improving psychosocial services [37]. Our sample population were all recruited from the metropolitan district; therefore caution is required when extrapolating these findings to the rural community.

\section{Conclusions}

Limited resources mean that service providers are unable to offer adequate support services, resulting in service provision that is patchy and varied. This research supports the role for evidence-informed service redesign to increase efficiency of support services to improve patient and carer wellbeing. Providing the types of support services that people prefer should maximise the use of limited resources. This study suggests that AYA patients with cancer or a blood disorder prefer support services that included financial aid, assistance returning to work/study, emotional support for themselves and for their family. We also demonstrate that there was reassuring symmetry between the preferences of AYA and their nominated carer.

\section{Conflicts of interest}

None declared 


\section{References}

1. Adolescent and Young Adult Oncology Progress Review Group, Closing the gap: Research and care imperatives foradolescents and young adults with cancer. 2006, U.S. Department of Health and Human Services, National Institutes of Health, National Cancer Institute, and the LIVESTRONG Young Adult Alliance.

2. Hawkins, M.M., Long-term survivors of childhood cancers: what knowledge have we gained? Nat Clin Pract Oncol, 2004. 1(1): p. 26-31.

3. National Breast Cancer Centre National Cancer Control Initiative, Clinical practice guidelines for the psychosocial care of adults with cancer. 2003, National Breast Cancer Centre: Sydney.

4. Devine, E.C. and S.K. Westlake, The effects of psychoeducational care provided to adults with cancer: meta-analysis of 116 studies. Oncol Nurs Forum, 1995. 22(9): p. 1369-81.

5. Meyer, T.J. and M.M. Mark, Effects of psychosocial interventions with adult cancer patients: a meta-analysis of randomized experiments. Health Psychol, 1995. 14(2): p. 101-8.

6. National Institute for Clinical Excellence, Guidance on Cancer Services: Improving Supportive and Palliative Care for Adults with Cancer. The Manual. 2004, National Health Service: London.

7. $\quad$ Rankin, N.M., et al., Psychosocial oncology services in New South Wales. Aust Health Rev, 2011. 35(2): p. 156-63.

8. McGrath, P., Identifying support issues of parents of children with leukemia. Cancer Practice, 2001. 9(4): p. 198-205.

9. Woodgate, R., Part II: a critical review of qualitative research related to children's experiences with cancer. Journal of Pediatric Oncology Nursing, 2000. 17(4): p. 207-228.

10. Politis, C., et al., Social integration of the older thalassaemic patient. Archives of Disease in Childhood, 1990. 65(9): p. 984-986.

11. Tsiantis, J., Family reactions and relationships in thalassemia. Annals of the New York Academy of Sciences, 1990. 612: p. 451-461.

12. Satterwhite, B.B., Impact of chronic illness on child and family: an overview based on five surveys with implications for management. International Journal of Rehabilitation Research, 1978. 1(1): p. 7-17.

13. Cadman, D., et al., Chronic illness, disability, and mental and social wellbeing: findings of the Ontario Child Health Study. Pediatrics, 1987. 79(5): p. 805-813.

14. Zani, B.D., A. Vullo, C., Psychological aspects of chronic illness in adolescents with thalassemia major. Journal of Adolescence, 1995. 18: p. 5.

15. Broadhead, W.E., et al., The epidemiologic evidence for a relationship between social support and health. American Journal of Epidemiology, 1983. 117(5): p. 521-537.

16. Ell, K., Social networks, social support and coping with serious illness: the family connection. Social Science \& Medicine, 1996. 42(2): p. 173-183.

17. Katz, E.R. and J.W. Varni, Social support and social cognitive problemsolving in children with newly diagnosed cancer. Cancer, 1993. 71(10 Suppl): p. 3314-3319.

18. Neville, K., The relationships among uncertainty, social support, and psychological distress in adolescents recently diagnosed with cancer. Journal of Pediatric Oncology Nursing, 1998. 15(1): p. 37-46. 
19. Nurmi, J.E., How do adolescents see their future? A review of the development and future orientation and planning. Development Review, 1991. 11(5): p. 159.

20. Nichols, M.L., Social support and coping in young adolescents with cancer. Pediatric Nursing, 1995. 21(3): p. 235-240.

21. Kyngas, H., et al., Coping with the onset of cancer: coping strategies and resources of young people with cancer. European Journal of Cancer Care, 2001. 10(1): p. 6-11.

22. Bush, S., F.S. Mandel, and P.J. Giardina, Future orientation and life expectations of adolescents and young adults with thalassemia major. Annals of the New York Academy of Sciences, 1998. 850: p. 361-369.

23. Mitchell, W., et al., Care and support needs of children and young people with cancer and their parents. Psycho-Oncology, 2006. 15(9): p. 805-816.

24. Sloper, P., Predictors of distress in parents of children with cancer: $a$ prospective study. Journal of Pediatric Psychology, 2000. 25(2): p. 79-91.

25. Soothill, K., et al., Informal carers of cancer patients: what are their unmet psychosocial needs? Health \& Social Care in the Community, 2001. 9(6): p. 464-475.

26. Corden, A., P. Sloper, and R. Sainsbury, Financial effects for families after the death of a disabled or chronically ill child: a neglected dimension of bereavement. Child: Care, Health \& Development, 2002. 28(3): p. 199-204.

27. Yantzi, N., et al., The impacts of distance to hospital on families with a child with a chronic condition. Social Science \& Medicine, 2001. 52(12): p. 17771791.

28. Lancaster, K., A new approach to consumer theory. Journal of Political Economy, 1966. 74(2): p. 132.

29. Lancsar, E. and E. Savage, Deriving welfare measures from discrete choice experiments: inconsistency between current methods and random utility and welfare theory. Health Econ, 2004. 13(9): p. 901-7.

30. Mark, T.L. and J. Swait, Using stated preference and revealed preference modeling to evaluate prescribing decisions. Health Econ, 2004. 13(6): p. 56373.

31. Ewing, J.E., M.T. King, and N.F. Smith, Validation of modified forms of the PedsQL generic core scales and cancer module scales for adolescents and young adults (AYA) with cancer or a blood disorder. Qual Life Res, 2009. 18(2): p. 231-44.

32. McFadden, D., Conditional logit analysis of qualitative choice behaviour, in Frontiers in Econometrics, P. Zarembka, Editor. 1974, Academic Press: New York. p. 105-142.

33. McFadden, D. and K. Train, Mixed MNL models for discrete response. Journal of Applied Econometrics, 2000. 15: p. 447-470.

34. Enskar, K., et al., Symptom distress and life situation in adolescents with cancer. Cancer Nursing, 1997. 20(1): p. 23-33.

35. Bessel, A.G., Children Surviving Cancer: Psychosocial Adjustment, Quality of Life, and School Experiences. Exceptional Children (2001 The Council for Exceptional Children), 2001. 67(3): p. 345-359.

36. Taylor, E.J. and E.J. Taylor, Nurses caring for the spirit: patients with cancer and family caregiver expectations. Oncology Nursing Forum, 2003. Online. 30(4): p. 585-590. 
37. Underhill, C., et al., Mapping oncology services in regional and rural Australia. Aust J Rural Health, 2009. 17(6): p. 321-9. 


\section{Tables \& figures}

\section{Table 1: Attributes and levels}

\begin{tabular}{|c|c|c|}
\hline Attributes & Description & Levels \\
\hline $\begin{array}{l}\text { Cultural/Ethnic } \\
\text { support }\end{array}$ & $\begin{array}{l}\text { Whether staff discuss options regarding cultural } \\
\text { or ethnic needs }\end{array}$ & Yes; no \\
\hline Spiritual support & $\begin{array}{l}\text { Whether staff discuss options regarding spiritual } \\
\text { or religious needs }\end{array}$ & Yes; no \\
\hline Financial support & $\begin{array}{l}\text { Staff provide information about the availability } \\
\text { and access of financial support }\end{array}$ & Yes; no \\
\hline $\begin{array}{l}\text { Returning to } \\
\text { work/study support }\end{array}$ & $\begin{array}{l}\text { Help to make your transition back to work or } \\
\text { study much smoother. E.g. assistance with } \\
\text { mobility, specialist teacher to help catch-up. }\end{array}$ & Yes; no \\
\hline $\begin{array}{l}\text { Emotional support for } \\
\text { you (your child*) }\end{array}$ & $\begin{array}{l}\text { Emotional support is offered by a } \\
\text { counsellor/psychologist, a peer, both or neither. }\end{array}$ & $\begin{array}{l}\text { None; counsellor; peer; } \\
\text { counsellor \& peer }\end{array}$ \\
\hline $\begin{array}{l}\text { Emotional support for } \\
\text { (you and*) your family }\end{array}$ & $\begin{array}{l}\text { Emotional support is offered to the family by a } \\
\text { counsellor/psychologist, a peer, both or neither. }\end{array}$ & $\begin{array}{l}\text { None; counsellor; peer; } \\
\text { counsellor \& peer }\end{array}$ \\
\hline
\end{tabular}

* refers to carer DCE only 
Table 2: Clinical and socio-demographic status of AYA and proxies

\begin{tabular}{|c|c|c|c|c|}
\hline & \multicolumn{2}{|c|}{$\begin{array}{c}\text { Adolescents and young } \\
\text { adults }\end{array}$} & \multicolumn{2}{|c|}{ Nominated proxies } \\
\hline & $\mathrm{N}=78$ & $(\%)$ & $\mathrm{N}=74$ & $(\%)$ \\
\hline \multicolumn{5}{|l|}{ Gender } \\
\hline Male & 38 & $(48.7)$ & 11 & $(14.9)$ \\
\hline Female & 40 & $(51.3)$ & 63 & $(85.1)$ \\
\hline \multicolumn{5}{|l|}{ Age } \\
\hline $15-19 \mathrm{yrs}$ & 42 & $(53.8)$ & - & - \\
\hline $20-29$ yrs & 36 & $(46.2)$ & 4 & $(5.4)$ \\
\hline $30-39$ yrs & - & - & 9 & $(12.2)$ \\
\hline $40-49$ yrs & - & - & 44 & $(59.5)$ \\
\hline $50-59$ yrs & - & - & 16 & (21.6) \\
\hline $60+y r s$ & - & - & 1 & (1.4) \\
\hline \multicolumn{5}{|l|}{ Ethnic group } \\
\hline European descent & 61 & $(78.2)$ & 61 & $(82.4)$ \\
\hline other & 17 & $(21.8)$ & 13 & $(17.6)$ \\
\hline \multicolumn{5}{|l|}{ Marital Status } \\
\hline Single & 62 & $(79.5)$ & 2 & $(2.7)$ \\
\hline Married / defacto & 15 & $(19.2)$ & 64 & $(86.5)$ \\
\hline Separated/divorced & 1 & $(1.3)$ & 7 & $(9.5)$ \\
\hline Widowed & & $(0)$ & 1 & (1.4) \\
\hline \multicolumn{5}{|l|}{ Educational status } \\
\hline $12^{\text {th }}$ grade or less & 39 & $(51.3)$ & 25 & $(33.8)$ \\
\hline High school certificate & 14 & $(18.4)$ & 13 & (17.6) \\
\hline Tertiary cert. course & 13 & $(17.1)$ & 19 & $(25.7)$ \\
\hline Graduate / prof. degrees & 10 & $(13.2)$ & 17 & $(23.0)$ \\
\hline \multicolumn{5}{|l|}{ Illness } \\
\hline Cancer & 58 & $(74.4)$ & - & - \\
\hline Blood disorder & 20 & $(26.6)$ & - & - \\
\hline \multicolumn{5}{|l|}{ Current status } \\
\hline Ongoing/in relapse & 23 & $(29.5)$ & - & - \\
\hline In remission & 55 & $(70.5)$ & - & - \\
\hline \multicolumn{5}{|c|}{ Required hospital overnight visit* } \\
\hline Yes & 57 & $(77.0)$ & - & - \\
\hline No & 17 & $(23.0)$ & - & - \\
\hline Missing & 4 & - & - & - \\
\hline \multicolumn{5}{|l|}{ Required a carer* } \\
\hline Yes & 60 & $(77.9)$ & - & - \\
\hline No & 17 & $(22.1)$ & - & - \\
\hline Missing & 1 & - & - & - \\
\hline
\end{tabular}

$\mathrm{N}=$ number included in the analysis, Percentages exclude missing values.

* Within the last 12 months 


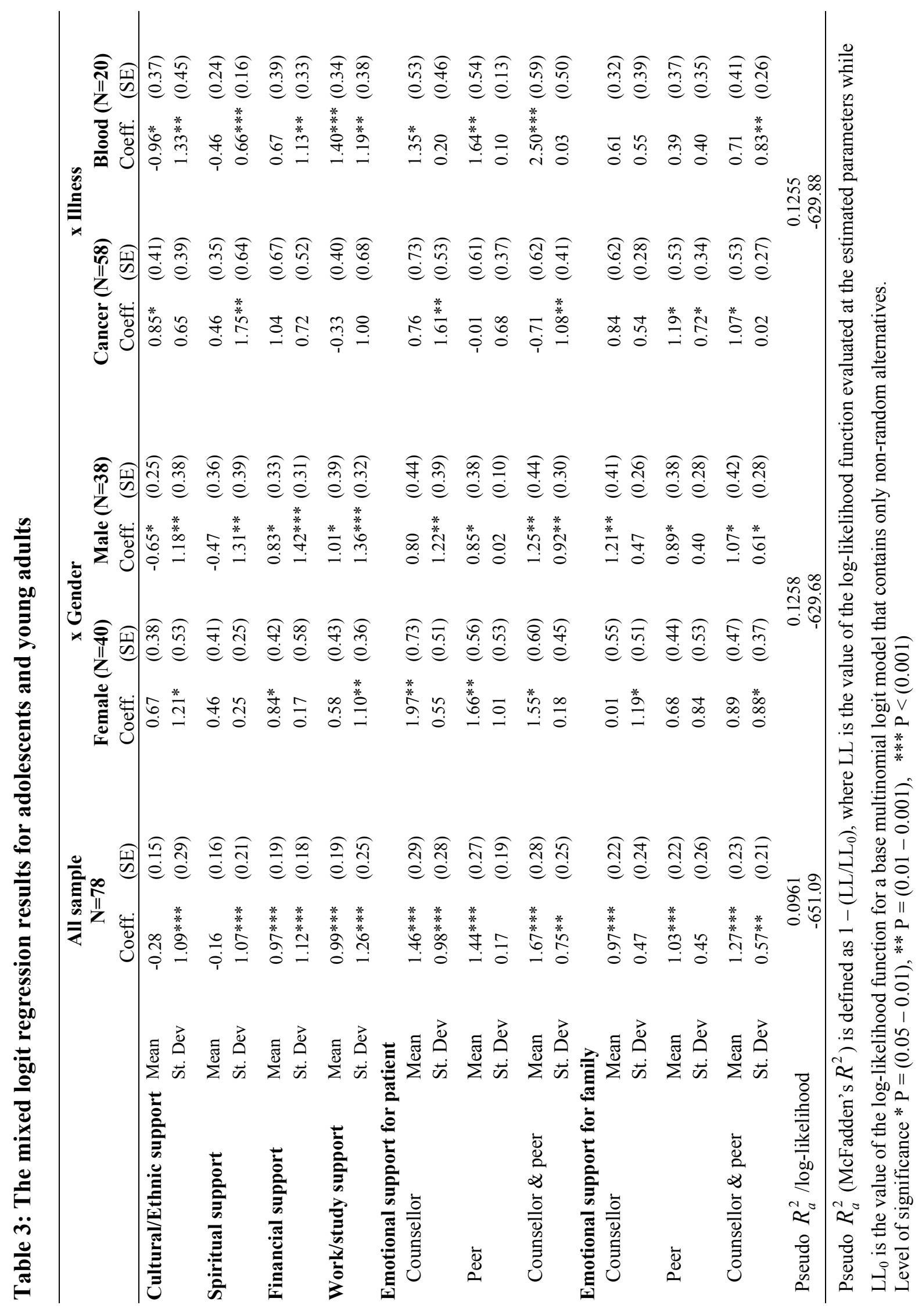


Table 4: The mixed logit regression results for Proxies

\begin{tabular}{|c|c|c|c|}
\hline & & & mple \\
\hline & & & \\
\hline & & Coeff. & $(\mathrm{SE})$ \\
\hline Cultural/Ethnic support & Mean & -0.21 & $(0.13)$ \\
\hline & St. Dev & $0.72^{* *}$ & $(0.26)$ \\
\hline Spiritual support & Mean & 0.30 & $(0.18)$ \\
\hline & St. Dev & $1.08^{* * *}$ & $(0.21)$ \\
\hline Financial support & Mean & $0.83^{* * *}$ & $(0.16)$ \\
\hline & St. Dev & $0.73^{* *}$ & $(0.21)$ \\
\hline Work/study support & Mean & $1.28^{* * *}$ & $(0.25)$ \\
\hline & St. Dev & $1.15^{\star * *}$ & $(0.23)$ \\
\hline Emotional support for pat & & & \\
\hline Counsellor & Mean & $1.71^{* * *}$ & $(0.34)$ \\
\hline & St. Dev & $1.08^{* * *}$ & $(0.23)$ \\
\hline Peer & Mean & $1.51^{* * *}$ & $(0.28)$ \\
\hline & St. Dev & 0.46 & $(0.29)$ \\
\hline Counsellor \& peer & Mean & $1.94^{* * *}$ & $(0.31)$ \\
\hline & St. Dev & $0.90^{* * *}$ & $(0.20)$ \\
\hline Emotional support for fam & & & \\
\hline Counsellor & Mean & $0.45^{*}$ & $(0.19)$ \\
\hline & St. Dev & 0.17 & $(0.22)$ \\
\hline Peer & Mean & $0.51^{* *}$ & $(0.18)$ \\
\hline & St. Dev & 0.12 & $(0.11)$ \\
\hline Counsellor \& peer & Mean & $0.75^{\star *}$ & $(0.19)$ \\
\hline & St. Dev & $0.44^{*}$ & $(0.22)$ \\
\hline Pseudo $R_{a}^{2}$ log-likelihood & & & \\
\hline
\end{tabular}

Pseudo $R_{a}^{2}$ (McFadden's $R^{2}$ ) is defined as $1-\left(\mathrm{LL}_{\mathrm{LL}}\right)$, where $\mathrm{LL}$ is the value of the log-likelihood function evaluated at the estimated parameters while $\mathrm{LL}_{0}$ is the value of the log-likelihood function for a base multinomial logit model that contains only non-random alternatives.

Level of significance * $\mathrm{P}=(0.05-0.01), * * \mathrm{P}=(0.01-0.001), \quad * * * \mathrm{P}<(0.001)$ 
Figure 1: Predicted probability" of choosing different types of support for patients and carers

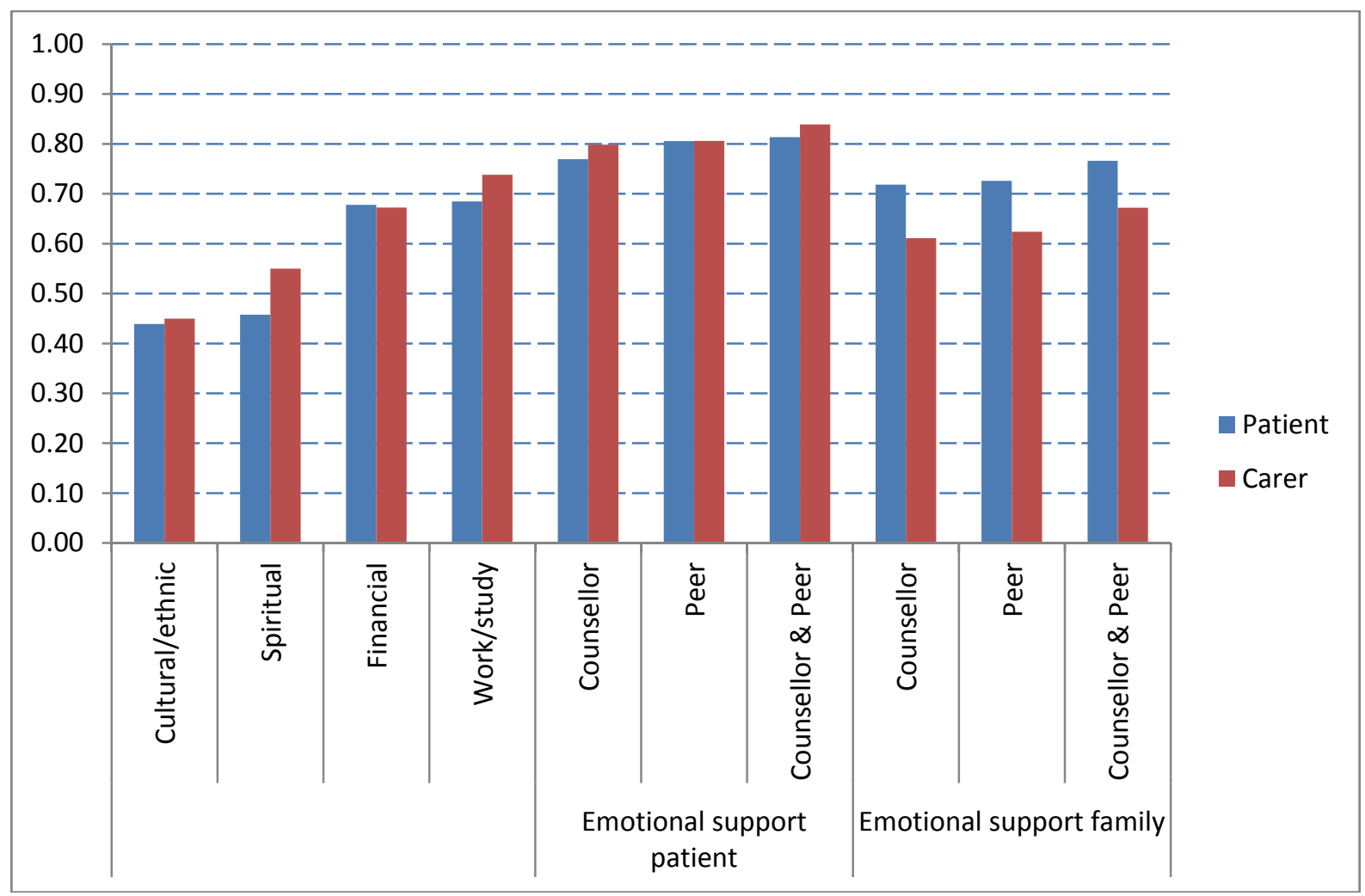

*The probability of choosing a support plan if the service is provided, 0.50 indicates indifference between the two plans when the service is provided. 